\title{
Bogans in the news: A case of media reflexivity
}

\section{ABSIRACI}

In March 2007, the New Zealand government announced the outcome of its competitive funding round for Top Achiever Doctoral Scholarships. This article traces the news controversy emerging with the awarding of a scholarship for the first author to study the everyday lives of Bogans. Across radio, newspaper and television news outlets tensions emerged regarding the (mis)use of public monies, representations of Bogans, and common understandings of academic research. The authors document their efforts to extend news deliberations beyond negative reactions to the scholarship.

Keywords: Heavy metal; news; advocacy; public intellectual

\section{DAVE SNELL and DARRIN HODGETTS}

\section{Waikato University}

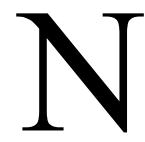

TEW ZEALAND readers may be familiar with recent news scandals regarding the allocation of public funds to support hip-hop tours (Agency tells how cash for hip-hop trip doled out, New Zealand Herald, 20 March, 2004) and research into the female orgasm (PM seeks details on academic funding 'corruption', New Zealand Herald, 12 October 2006). Such stories focus on the presumed (mis)use of public funds to support what are constructed as fringe projects of limited social benefit. These stories often exemplify a media template (Kitzinger, 1999) or set news frame that is rewritten to feature new examples of existing plotlines. Media templates serve as a form of rhetorical shorthand that is cultivated among journalists and audiences over time as part of popular knowledge. Templates are used to make sense of and communicate emerging events, often with reference to 'similar' events from the past ( $c f$., Edy \& Daranova, 2006). The prominence of the (mis)use template is enhanced by the simplicity of a plotline that presents clear links between causes, consequences and solutions, and relies on stock characters such as politicians and researchers.

Recently the (mis)use template was applied to coverage of the awarding 
of a Top Achiever Doctoral scholarship to support the first author's investigation of the everyday lives of Bogans. This article documents the news controversy surrounding the awarding of the scholarship and considers the potential of reflexive moments in news for extending coverage beyond the (mis)use template. We demonstrate the importance of scholars responding to opportunities created by news controversy regarding their work by engaging with journalists to promote the significance of academic endeavors.

The use of public funds to support academic research is contested and in the present case was woven into ongoing struggles for political power. For example, when announcing the funding of the doctoral scholarships, the Finance Minister, Dr Michael Cullen, proposed that the awards underpinned the New Zealand knowledge economy and would benefit the country economically. The release emphasized a central preoccupation for the current monetaristorientated government in targeting public funds to economic investment ( $c f$., Cheyne, O’Brien \& Belgrave, 2005). In response a National party member of Parliament, Dr Paul Hutchison, questioned how a scholarship to study the everyday lives of Bogans would support the governments' stated economic agenda. In subsequent news reports it was proposed that this was yet another example of government misusing public funds in support of fringe projects. Such exchanges exemplify how minority groups, such as Bogans, can be stereotyped for rhetorical purposes and used in a broader game of political point scoring ( $c f$. ., Cottle, 2003; McNair, 2004).

It is useful at this point to clarify what we mean by the term Bogan. The term originated in Australia as a label for irresponsible and often unemployed teenage males (Brown \& Brown, 2005). In New Zealand, the term is often used interchangeably with 'westy' or 'metaller' to identity members of a subculture who wear black clothing, consume heavy metal music, drink alcohol excessively, and often drive modified cars. A comparable term in the United States is 'trailer trash'. Bogans are stereotyped as working class, unproductive, white males who have limited intelligence and reside on the fringes of society, both economically and socially. Such stereotypes are inaccurate in that there are Asian, Māori, Pacific Island, Pakeha and female Bogans. Further, many Bogans have professional qualifications and jobs - including journalism.

Strong lobbying by powerful political groups can reduce opportunities for depth in reporting, public deliberations about issues, and opportunities for the voicing of alternative perspectives that highlight the problematic na- 
ture of stereotypes used in news stories ( $c f$. , Berkowitz \& Terkeurst, 1999). Coverage may be reduced to the perspectives of those with the resources and political legitimacy to lobby journalists (Thorson, 2006). As a result news production has been conceptualised as a closed system only engaged in politically powerful groups (Cottle \& Rai, 2006). Such thinking has contributed to a situation where academics and representatives of marginalised communities often see news media and journalists as 'the enemy' to be avoided unless one wants 'to get burnt' ( $c f$. ., Fenton et al., 1998). It is important to not become overly pessimistic with regard to the influence of political elites on the openness of news processes. As well as subverting the free flow of information, lobbying can be used to open up deliberations regarding social issues (McNair, 2004). Hodgetts and colleagues (2008) found that New Zealand journalists reflected critically on the role of political spin in news production and often resisted the agenda setting activities of powerful groups by advocating for marginalised groups. As Cottle \& Rai, (2006: 164) note, '... Simply put, there is more going on in the communication of news than the manipulation of news agendas by powerful strategic interests or the circulation of powerful semiotic codes and agendas'.

Our efforts to reframe negative news responses to the scholarship incident are informed by Roger Silverstone's writing on media as public forum. Silverstone (2007) introduces the concept of the mediapolis to explain the presence of media in contemporary civic life as an extension of the ancient Greek polis; the shared civic space in a society where political communication occurred:

Contemporary media...reproduce, though of course in an intensely technologically mediated form, the discursive and judgmental space of the polis. Like the polis this mediated space is often, indeed mostly, elitist and exclusive. Like the polis it depends on visibility and appearance in the media... Increasingly what passes for public life in contemporary societies takes place, more or less exclusively, on the screen (Silverstone 2007, p. 29-31).

The concept of mediapolis invokes an image of citizens engaged via media in a regulated, but pluralistic symbolic space where controversy can take shape and be worked through. Importantly, the mediapolis is seen as extending beyond the screen or page onto face-to-face conversations and 
interactions between citizens. In the present case, newspaper readers are offered glimpses, interpretations, commentary, and assertions regarding the allocation of public funds to research Bogans. They can also engage in conversations and debate about such events face-to-face in workplaces and cafés, as well as via the media though letters, talkback calls, and postings on online websites.

For us, what is significant about the concept of the mediapolis is that it maintains a notion of communicative restraint in terms of the activities of political elites and the potential for extending civic participation via news media through the inclusion of less powerful voices. We propose that increased diversity of perspectives in the mediapolis can be detected in specific instances such as when journalists pause and reflect on the ways in which events are being covered, groups are characterised, and who is and is not included in shaping an evolving story ( $c f$. , Edy \& Daranova, 2006). Reflecting on such instances, Cottle and Rai (2006) identified the 'reportage' news frame in stories aimed at generating deeper insights into events by providing audiences with background information, including first-hand testimony from those directly affected. News media reflexivity involves a self-conscious consideration of the framing of events during news flows, which renders visible aspects of news construction, prominent trends in coverage, and directions for future reports. For instance, an opinion piece (Back in black: Bogan and proud, Waikato Times, 14 April 2007) written by a journalist and self-confessed Bogan presents a self-conscious defence of the Bogan lifestyle and challenges stereotypes of Bogans evident in previous news reports. Such items provide meta-commentaries on the evolving scholarship story and offer opportunities for alternative perspectives to enter the mediapolis.

\section{The present study}

This case study is designed to provide insights into media deliberations regarding the use of public funds for academic research. Our approach emphasises the need for researchers to respond to controversy regarding their work as it arises in the news. As Law (2004, p. 7) states:

Since social (and natural) science investigations interfere with the world, in one way or another they always make a difference, politically and otherwise. Things change as a result. The issue, then, is not to seek disengagement but rather with how to engage... 
Entering a news controversy over the funding of our research is one such mode of engagement. It is an action that is warranted given that research on the mediation of social science suggests that when concerted efforts are made by scholars to engage with journalists, both can benefit in terms of extending public deliberations regarding issues of social concern (Fenton et al., 1998). Such efforts enact our traditional role as public intellectuals with an obligation to share knowledge with the wider citizenry who fund our efforts (cf., Posner, 2001).

It was necessary to look across a range of broadcast and print media forms because various news outlets contributed to the evolving story. For instance, along with newspapers, television and radio provided the initial coverage of this issue on 28 March 2007. The negative political attention given to the scholarship at this stage resulted in news outlets requesting interviews with us. Subsequent interviews with journalists enabled us to present an alternative perspective on the research and, along with members of the Bogan community, challenge negative assumptions regarding Bogan culture. Subsequently the story was extended through newspaper editorials, commentaries and letters, where competing views from various stakeholders were expressed in more detail. Coverage culminated in a television current affairs item and associated response letters, which illustrate the extension of the mediapolis into daily life and web-based arenas.

To document the emerging story we obtained as many news items as possible $^{1}$ from the highest rating television network $($ TVNZ) $(n=4)$, public service and commercial radio $(\mathrm{n}=5)$ and various newspapers $(\mathrm{n}=16)$. Audience letters were particularly important because they constitute public reactions to media reports and reflect current trends towards overt audience participation in news production (Hodgetts et al., 2008). All news outlets were treated as sites for social practice through which common knowledge is articulated and circulated to the broader citizenry. Our analysis explores the role of news media in the negotiation of such popular knowledge through detailed attention to the evolving story and the presentation of insights from the journalism and communications literatures. Specifically, the entire corpus of coverage was read by both authors independently to identify prominent issues for analysis. We then met to discuss emerging themes and developed a table outlining the date of publication, type of media item (e.g. editorial), news outlet, and item focus. This table provided an overview of coverage 
and allowed us to follow the story's evolution over time and across media. The resulting analysis is presented in three parts. The first focuses on initial coverage and challenges to the legitimacy of the Bogan study. We consider our efforts to extend initial news deliberations and associated instances of news media reflexivity. The second extends our discussion of news reflexivity through an analysis of the current affairs programme. The third documents continued public deliberations of core issues through audience responses to news coverage and the ways these are incorporated back into news items.

\section{Initial coverage and efforts to score political points}

The story needs to be considered in the context of ongoing political struggles and how relationships between journalists and sources, such as politicians, are central to the power to name and define issues (Berkowitz \& Terkeurst, 1999). This power is often contested. This is evident in the juxtaposing of the Finance Minister's announcement of the intent of the scholarships as investments in the economy and the questioning of such 'investments' by a National Party opposition member of Parliament. For instance, Radio New Zealand was one of the first outlets to broadcast an item on the scholarship story (\$96,000 for Bogan study, 28 March 2007). The item begins by outlining the funding allocation and then refers to a Wikipedia definition of Bogan as 'a generally pejorative term for a person who is, or is perceived to be, unsophisticated or of a lower class background. The term is related to uneducated working class white people'. The focus turns to the government's stated aim for the scholarships, which is juxtaposed with opposition queries regarding the suitability of a study of 'uncultured' Bogans:

The scholarships announced this week, were described by Tertiary Minister Michael Cullen as a great investment in the types of research that are underpinning the country's transformation into a knowledge economy.

But National's tertiary spokesperson, Paul Hutchison, says it is very difficult to see how a study on Bogans is going to do that...

We need to consider the functioning of the traditional journalistic norm of balance in the establishment of the scholarship story as being controversial. Balance involves attempts to present both sides of a story from a 
neutral point of view (Hodgetts et al., 2008). The juxtaposition of testimony from government spokespeople and an opposition politician provides a means of achieving balance, where a challenge can be raised and a response aired and the story extended through debate. This convention has been criticised for reducing issues to two opposing views presented in a 'balanced' manner, which can displace the ideal of reporting on a range of perspectives, verification and depth ( $c f$., Singer, 2006). Focusing on the differing and adversarial perspectives of political elites can also come at the cost of stigmatising social groups who are the focus of discussion. We were aware of such limitations when considering how to intervene in the evolving story and promote alternative perspectives in order to extend the story beyond a closed political point scoring exercise.

As the controversy built momentum and journalists became interested in establishing further depth, space emerged for extending the story through the introduction of alternative views. We decided to step up our participation in the mediapolis by promoting three key messages.

Firstly, in response to the Minister's initial comments regarding grants contributing to the knowledge economy and the response of an opposition MP, we proposed that 'not everything is about the economy'. We emphasised the need to develop informed understandings of different social groups if we are to build a tolerant society. Second, we promoted the fact that Bogans are citizens whose lives have not been given sufficient academic attention and who comprise a significant proportion of the population. This involved identifying Bogans that journalists could consult regarding the scholarship and the ways in which they were being depicted in the news. In the process, we challenged the stereotype of the uncultured, unintelligent and disruptive outsider by emphasising diversity among Bogan trades people, accountants, teachers and journalists. Third, we emphasised the competitive nature of the scholarships, cutting-edge nature of the research, and the need to support, train and retain talented young researchers. This involved emphasising that it is not solely what a $\mathrm{PhD}$ candidate studies, but also the skills he or she develops from conducting independent research at this level that would be of benefit to New Zealand. We engaged all news outlets from a consistent line that emphasised these key messages ( $c f$. . McNair, 2004). Correspondingly, we adopted two different roles in our media appearances. The first author presented as the promising young researcher and friendly Bogan. The second 
author presented as the 'impartial' academic who was concerned for a talented student whose work was of national and international significance, and who was being unfairly used as a political pawn.

Editorials from the Waikato Times and New Zealand Herald suggest some success in our efforts to promote key messages and alternative perspectives. Bogans are people too (Waikato Times, 3 April 2007) provides an example of how our messages were integrated into the evolving story. The editorial provides an example of 'reportage' (Cottle \& Rai, 2006) or a journalist pausing to consider perspectives in an evolving story. The editor begins with questions about whether all Bogans are Heavy Metal fans while proposing that:

No doubt Mr Snell could probably offer an interesting reply..., but it's doubtful whether the politicians, who have helped propel him to national prominence, would be willing to listen.

Unfortunately Mr Snell has become that most distasteful of pariahs, the political pawn. His chosen thesis topic has been seized on by National MP Paul Hutchison as an example of everything that is wrong with Labour's economic policy...

In fact Dr Hutchison's point is to embarrass the government for handing over $\$ 96,165$ to assist Mr Snell with his bogan study over the next three years. Mr Snell is unfazed and says 'not everything' is about economics. And praise be for that, we say. He is particularly interested in changing the negative stereotypes about metal — a noble aim that may eventually result in a more productive minority...

It doesn't take a doctorate to know that those skills, which will eventually be applied in the workplace, do have a direct economic benefit. It's impossible to know where Mr Snell's study will take him, but it is highly probable his thesis will contribute to a better understanding and knowledge of a sector of New Zealand society ...

Dr Hutchison's attack on Mr Snell's chosen field of study was cheap and opportunistic. Scrutiny of grants for academic research is a rigorous process that shouldn't always be underpinned by economic benefit.

A similar stance was adopted in a New Zealand Herald editorial (All the better to understand bogans, 8 April 2007). This time more emphasis was placed on criticisms that the money would have been better spent on other more worthy endeavors: 
...It's easy to argue that the money might be better spent elsewhere, but it's all a question of your point of view. A careless cyclist might argue that money spent on motorways is money wasted. But any research that helps us understand more about social subcultures is useful. Who objects to the funding of research into gangs? Sex workers? Drug users?

Such items provide commentary on the evolving story and function to broaden public deliberations regarding the topic of concern. In this case, the editors advocated on behalf of a student who had been co-opted into a broader political confrontation. This confrontation was identified as a driving force behind the controversy. The editorials drew on several points from our key messages, including the fact that not everything is about the economy, the unfairness of Dave Snell being used as a political pawn, the importance of research into groups such as Bogans, and how a $\mathrm{PhD}$ topic is often less important than the skills a student gains from conducting research at the highest level. Such items illustrate how, when faced with criticisms from political elites, scholars can do more than simply retreat from and become cynical about news production processes. We can engage in counter spin to challenge politically motivated, narrow and negative assessments of our research. In the process we can support journalists in questioning efforts to stigmatise and dismiss minority groups. This includes reflections on who is attempting to mould coverage to such ends (cf., Edy \& Daranova, 2006). Initial coverage also exemplifies McNair's (2000) proposition that news stories can be conceptualised as situations for action and reaction. Stories involve various instances of manufactured exchange between public figures and stakeholders, where each 'move' forms the context and condition for the next 'move'. Any particular point in the evolving story is contingent on previous installments that can be referred back to in a reflexive manner when contemplating new insights and directions for a story (cf., Clayman, 2006).

\section{0/20 and news media reflexivity}

A core aim of our contributions to coverage was to challenge negative stereotypes of Bogans. Within the first week of the controversy we were approached by current affairs journalists from 20/20 regarding our willingness to participate in an item on the research project and controversy. During our first face-to-face meeting the journalists stated that they were interested 
in challenging negative stereotypes of Bogans and we agreed to take part in the item. Filming took two weeks and included an on-campus gig (organised by Dave). Such events have been referred to as opinion-shaping events that are designed to attract and sustain audience attention in order to enhance the likelihood of one disseminating key messages (McNair, 2004). Bogans Heroes aired on 3 May 2007. The opening sequence begins with a montage of images from the gig depicting Metallers dressed in black and dancing to hard rock music. The voiceover states:

They've slugged their cut price liquor, slapped on their favorite black jeans, now they're ready to rumble...welcome to a Bogan's night out. Now see the guy with the goatee beard, keep an eye on him, cause you and I have just invested $\$ 96,000$ in his education. Over the next three years you will pay for his university fees, living expenses...even a trip to Portugal. But don't despair, Dave is diligent. In fact you could say he's studying right now... This may be the cheekiest stunt a Bogan's ever pulled or a legitimate study of a group long viewed with contempt by society...

This sequence begins along a similar vein to previous reports relying on stereotypical representations of Bogans and public anxieties regarding the (mis)use of public funds. However, there is a conscious shift in the framing of the research from an example of the (mis)use of public funds to a more positive emphasis on the need to support a 'diligent' student and his research into a group comprised of members of 'our' community. This opening sequence sets the scene for the rest of the item, which invites the audience to consider an alternative perspective on the study and Bogans. Rhetorical devices such as the statement 'you and I have just invested...' positions the journalist as representing wider society who is speaking directly to viewers. This positioning strengthens later 'revelations' about Bogans being more like the rest of 'us' than has been conveyed in previous items emphasizing difference.

The deconstruction of popular misconceptions of Bogans as uneducated and mindless drunks is overt in a scene depicting Dave sitting on steps at the university alongside other students. Visuals convey an academic setting as the voiceover states: 'Don't be fooled by his lived in look, this Bogan is actually pretty smart'. The camera then depicts a young female student as the 
interviewer asks: 'Would it surprise you to learn that he's got a grade point average of over 90?' The student then responds in a surprised tone: 'Grade point, really? No, I don't mean that as REALLY? Like...I find that quite high even for a non-Bogan (laughs)'. The camera then cuts to a close-up of Darrin sitting in a lecture room as he testifies to Dave's academic credentials and the misconception that Bogans are not intellectually motivated or gifted.

This sequence conveys an image of Dave as a bright and educated young Bogan researcher who belongs in academia. The voiceover subsequently describes Bogans as 'a valid research topic'. This is a direct challenge to Paul Hutchison's criticisms of the allocation of the scholarship to a student who has 'pulled a fast one' and who is wasting public money.

The depiction of Bogans in a manner that disrupts stereotypical assumptions - previously central to the evolving scholarship story-continued as a core theme in the 20/20 item. Returning to the gig, the voiceover states: 'Tonight there are plenty of undercover Bogans coming out of the closet...' The camera then cuts to an image of a man with long hair and shaggy beard playing bass guitar and head banging as the voiceover states:

Like next year, this guy will be a primary school teacher... And Jake, champion head banger, will have a chemistry degree. There are also Bogan lawyers, Bogan bank staff and this woman,... she's a PA, mother of two, wife of 20 years, and prefers this crowd to normal bars any day...

The sequence presents Bogans as being educated and gainfully employed. It humanises Bogans as people with occupations and responsibilities. Bogans are presented as normal people who like loud music. This is highly significant in the context of the larger story in which the status of Bogans as citizens, normal and in fact even human ${ }^{2}$ is contested. The item ends with an extension of this theme when the voiceover accompanies more images from the gig and states:

Spend a night out with some Bogans and you'll find their look is purely superficial. They love the tough images, but the reality is different... cause despite a few munters running round, there were no fights and no trouble. It seems that Bogans are just regular guys, with a lot of love for some very loud music. 
This statement further emphasises how stereotypes are often inaccurate. The audience is confronted with the assertion that Bogans are also citizens and have a lot in common with 'us', the audience. The voiceover concludes that there may be 'a little Bogan in all of us'.

The 20/20 item invokes an 'invitational' form of news media reflexivity where the audience is invited to reflect on coverage to date and consider additional information that may challenge common stereotypical representations of Bogans. Such stories close the gap between journalists and the audience, where 'we' are encouraged to step back and make sense of news images with a larger frame of reference (Cottle \& Rai, 2006). The invitation relies on references to past coverage and popular knowledge of Bogans. Edy and Daranova (2006) propose that the past is often invoked in news stories as a basis for interpreting recent events and depictions of stakeholders in news coverage. According to these authors, appeals to collective memory of past reports on an issue are a core element of news narration because such appeals open up spaces for new developments and the reconsideration of the use of specific news frames in a story.

\section{Within and beyond the news: Audience deliberations}

Newspaper editorials and the 20/20 item were not the only reflexive instances in the evolving story. Throughout coverage newspapers and television stations solicited audience responses to the controversy. The inclusion of letters both supporting the scholarship and criticizing the award reflects the attempt of outlets to attract audience interest through controversy (Smith, McLeod \& Wakefield, 2005) and to simulate public dialogue through the juxtaposing of perspectives (Schudson, 2003). For instance, a letter to the Waikato Times (Bogan nonsense, 4 April 2007) presents a typical example of adverse audience reactions to the scholarship:

It sickens me to think of the less well-off members of the public paying taxes of $\$ 96,165$ for a student to gain a $\mathrm{PhD}$ on heavy metal music... I find it incredibly depressing (I am a mere 'ordinary mortal') to think what fools we have become to fund these 'quirky', so-called high-class qualifications. Could anyone from the Times enlighten me as to what they actually mean and how does spending almost $\$ 300,000$ by our government, on our behalf, benefit anyone in New Zealand other than these recipients? ROBYN McDOUGALL 
This letter writer presents as an 'ordinary' member of the community who is 'shocked' by this inappropriate use of public funds. The letter composition presents a variant of the 'misuse' of public funds template through a personalised account of 'disappointment'. Implicit to the letter is a notion of undemocratic and out of control spending being conducted by government on 'our behalf'. Thus, the letter is typical of those critical of the scholarship allocations.

Other letters were more supportive of the project and critical of negative reactions (Who really is the Bogan? Waikato Times, 10 April 2007):

It is amazing an educated man like Dr Paul Hutchison MP (Waikato Times, March 31) should snidely and condescendingly wonder in public how a particular bit of sociological research will 'transform the New Zealand economy' (as if that was its aim).

It leaves one wondering who, in fact, is the intellectual Bogan, and a pretty ill-mannered and selective one at that. After all, he obliquely derides only the heavy metal study and selectively lacks any curiosity as to how 'the application of derived relations to the enhancement of psychological therapy' or 'the spatially variant restoration of range images' is going to put us on the top of the financial heap.

DUNCAN McCORMACK

Such items exemplify a direct challenge to the negative perspective advocated by Paul Hutchinson and how he focuses his criticisms on one particular scholarship and not others that could be equally open to challenge. In the process this letter constitutes an attempt to negate negative reactions to the scholarship as partial and unfair.

Letters provide some indication of mixed community sentiments regarding this case (Smith et al., 2005) and the broader dialogical function of the mediapolis. Letters pages provide forums within which common knowledge is expressed and negotiated when rewoven into subsequent coverage. It is important to note that letters were not just responded to by further letters in a kind of confined sub-forum for public deliberation. They were taken up in later items by journalists, who are also members of the audience and as such respond to the story as it develops. The following item by Geoff Taylor (Back in black: Bogan and proud, Waikato Times, 14 April 2007) provides a reflexive account, integrating key points from previous letters and reports into a 
general opinion piece. The item begins with a tongue-and-cheek check list for readers to use in establishing whether or not they are actually Bogans who drive a Holden HQ, would save their stereo before the family photoalbum in the case of a fire, have a mullet or perm, and consider their own family life to be similar to the feature family of the television programme Outrageous Fortune' After outlining the grant story and negative reaction of Paul Hutchison, Geoff Taylor writes:

...Robyn McDougall, a Hamilton letter writer to the Times this week, said she was 'shocked, astounded and angered' to see taxpayers money spent on research into heavy metal. 'I find it incredibly depressing to think what fools we have become to fund these 'quirky', so-called high-class qualifications,' she wrote.

Why the reaction? Partly put it down to the 'b-word'. 'Bogan' evokes images of fans of heavy metal or hard rock, decked out in black jeans and t-shirts with mullet haircuts and facial hair, sipping on a Waikato Draught or Woodstock Bourbon and Cola and cruising in a Holden Kingswood, fluffy dice dangling from the rearview mirror. Uncultured, unsophisticated, unfashionable. But Bogans say we're missing something. Bogans are hard working, unpretentious, no nonsense types who simply enjoy their music. They're proud to be Bogans.

Look around, they say. You'll realise bogans are a common phenomenon. It's time their culture was documented. Maybe they're right...

The item brings into question the legitimacy of negative stereotypes underlying many criticisms of the Bogan study. The journalist normalises Bogans by presenting them as citizens and, therefore, worthy of academic attention. Humour is used to undermine negative reactions to the scholarship as over-reactions. The journalist legitimates his support for the study with reference to statements from Bogans who call for more understanding and acceptance of their chosen lifestyle and emphasise that Bogans are citizens. Again emphasis is placed on the importance of Dave's double role as a Bogan and researcher. Such items constitute instances of news media reflexivity in that they foreground commentary on trends in coverage and offer alternative perspectives based, in part, on further background information 
and first hand testimony from Bogans ( $c f$. , Cottle \& Rai, 2006). They also involve self-conscious consideration of the framing of events and groups and render visible aspects of news production. Specific reports are inherently inter-textual, often drawing on coverage from elsewhere in the news nexus and extending the evolving story accordingly. Issues raised through traditional news formats can also be taken up and worked through within entertainment forums, such as music radio shows.

Despite the 20/20 item and other reports providing depth to the story and alternative perspectives, it would be naïve to think that such items can completely resolve tensions emerging throughout the controversy. Audience responses remained contested. For example, during the next episode of 20/20 an email response was read by the programme host (10 March 2007):

\begin{abstract}
Dear 20/20, As a mum and a human, I am absolutely disgusted that a man who chooses to study Bogans is payed [sic] \$96,000 over three years to do so. This is outrageous. That is more money that an average New Zealander will ever see in three years yet all this man has to do is research a minute proportion of our society - research which will in no way better our society what so ever. $\$ 96,000$ could go to much better use i.e. medical research, saving lives, cancer research, care for the elderly or charity. But instead, society gets a thesis on Bogans.

Concerned mum.
\end{abstract}

It is important to reflect on who the terms 'mum', 'human' and 'New Zealander' refer to in this letter. From the letter composition it is unlikely to be Bogans. The self-reference to the writer as a 'mum and a human' invoke an 'us' and 'them' distinction central to processes of social marginalization. This distinction is used to position the letter writer as a spokesperson for the wider community and to position Bogans as outsiders. Recourse to the collective identity of a concerned parent provides a means for supporting criticism of the allocation of funding to such 'outsiders' (cf., Smith et al., 2005) and the marginal interests of 'a minute proportion of our society'. This letter challenges the claim that Bogans comprise a significant element in society. It exemplifies the continuing currency of the idea that public funds are better spent elsewhere. This example also supports the view that it is important to not overstate the impact of media deliberations for audience 
members whose views are often somewhat resilient even when faced with alternative perspectives. News items can become common reference points for face-to-face conversations. Supportive coverage such as the 20/20 item can be read as sources of pride in such conversations and aid in the discussion and dismissal of prejudicial views evident in other such items.

\section{Discussion}

The scholarship case documented above reflects aspects of the mediapolis (Silverstone, 2007) evident in exchanges between journalists and politicians, researchers, Bogans, and members of the general public. Not all agree on the merits of funding research into the everyday lives of Bogans. Nor should agreement be expected. What we have shown is that, despite ongoing criticisms of the narrow and reactionary focus of news tabloidisation (McNair, 2004), there are opportunities to extend and add depth to news-based public deliberations regarding the funding of such research. In the process, we have documented how it is possible to modify the application of the (mis)use of public funds template (Kitzinger, 1999), at least in application to a specific case. Some success in this regard has come from our focus on supporting instances of news media reflexivity ( $c f$., Cottle \& Rai, 2006). What remains to be seen is if critical reflections by journalists regarding the public funding of academic research remains solely linked to the present case or if it will have implications for broadening reporting on other such cases in the future. We suspect that the (mis)use template will remain a starting point for news framing and that involvement from scholars and affected groups will be necessary to broaden news coverage.

There is potential for improving civic engagements via news media if one accepts that journalists can be publicly reflexive and receptive to suggestions from scholars for expanding coverage of a controversial issue ( $c f$., Cottle \& Rai, 2006). Rather than complaining about the perceived closed nature of news production, we see an opportunity to cooperate and inform public conversations (Hodgetts et al., 2008). Such work is necessary to develop a mediapolis in which a broader range of citizen groups are represented in public deliberations that influence their lives (Silverstone, 2007). In order to enhance cooperation, social scientists need to develop better understandings of journalists' practices and political influences. This does not mean simply adding ourselves to the list of lobbyists trying to push particular agendas 
(McNair, 2004). We should engage directly with journalists in an attempt to broaden dialogue, rather than restrict information flows. This is about much more than being sources of information for journalists; it is about acting as colleagues with journalists and supplying information that meets their needs while staying faithful to the hopes and aspirations of groups for whom we are advocating. After all, news media rely on new information to continue a story and we can be effective in providing such information.

\section{Notes}

1. The story was picked up in more than 15 countries.

2. See letters in the third analysis section of this paper.

\section{References}

Berkowitz, D., \& Terkeurst, J. (1999). Community as interpretive community: Rethinking the journalist-source relationship. Journal of Communication, 49, pp. 125-136.

Brown, B. \& Brown, D. (2005). Beyond boganism. Journal of Popular Culture, 38(4), pp. 632-649.

Cheyne, C., O'Brien, M., \& Belgrave, M. (2005). Social policy in Aotearoa New Zealand: A critical introduction. Auckland: Oxford University Press.

Clayman, S.E. (2006). Understanding news media: The relevance of interaction.

In P. Drew, G. Raymond \& D. Weinberg. (Eds). Talk and interaction in social research methods (pp. 135-154). London: Sage.

Cottle, S . (2003). News, public relations and power. London: Sage

Cottle, S. \& Rai, M. (2006). Between display and deliberation: Analyzing TV news as communicative architecture. Media, Culture \& Society, 28, 163-189.

Edy, J., \& Daranova, M. (2006). Reporting through the lens of the past. Journalism, 7, pp. 131-151.

Fenton, N., Bryman, A., \& Deacon, D. (1998). Mediating Social Science. London: Sage.

Hodgetts, D., Chamberlain, K., Scammell, M., Nikora, L., \& Karapu, R. (2008). Constructing health news: Media production and the possibilities for a civic-oriented journalism. Health, 12 (1).

Kitzinger, J. (1999). The ultimate neighbour from hell? Stranger danger and the media framing of paedophiles. In B Franklin (Ed.). Social Policy, Media \& Misrepresentation (pp. 207-221). London: Routledge.

Law, J. (2004). After methods: Mess in social science research. London: Routledge.

McNair, B. (2004). PR must die: spin, anti-spin and political public relations in the UK, 1997-2004. Journalism Studies, 5, pp. 325-338.

McNair, B. (2000). Journalism and democracy. London: Routledge. 
Posner, R. (2001). Public intellectuals: A study of decline. Cambridge, Mass: Harvard University Press.

Schudson, M. (2003). The sociology of news. New York: W. W. Norton \& Company.

Silverstone, R. (2007). Media and morality: on the rise of the mediapolis. Polity: Cambridge.

Singer, J. (2006). The socially responsible existentialist: A normative emphasis for journalists in a new media environment. Journalism Studies, 7, 2-18.

Smith, K., McLeod, K., \& Wakefield, M. (2005). Australian letters to the editor on Tobacco: Triggers, rhetoric, and claims of legitimate voice. Qualitative Health Research, 15, pp. 1180-1198.

Thorson, E. (2006). Print news and health psychology: Some observations. Journal of Health Psychology, 11, pp. 175-182.

Dr Darrin Hodgetts is an associate professor and Dave Snell a doctoral student in the Department of Psychology, University of Waikato. This research was supported by grant No. 2397 from the Tertiary Education Commission of New Zealand.

dhdgetts@waikato.ac.nz

\section{AØ] COMMUNICATIONS}

\section{POSTIRADUATE,OURIALISM}

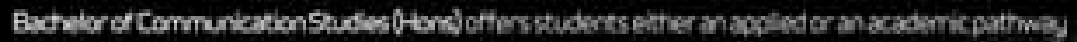

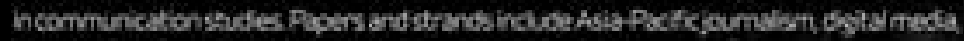

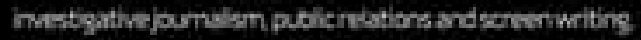

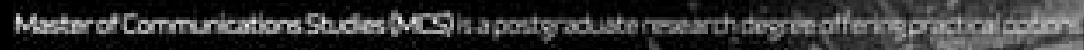

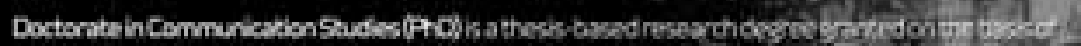

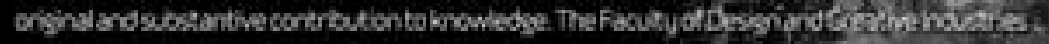

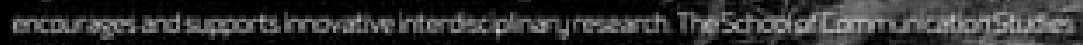

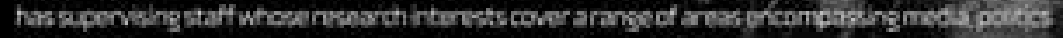

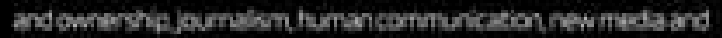

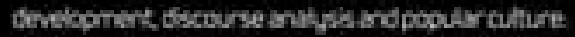

